\title{
Rebamipide, a Cytoprotective Drug, Increases Gastric Mucus Secretion in Human: Evaluations with Endoscopic Gastrin Test
}

\author{
Katsunori Iijima $\cdot$ T. Ichikawa $\cdot$ S. Okada $\cdot$ \\ M. Ogawa $\cdot$ T. Koike $\cdot$ S. Ohara $\cdot$ T. Shimosegawa
}

Received: 23 June 2008/Accepted: 22 August 2008/Published online: 31 October 2008

(C) The Author(s) 2008. This article is published with open access at Springerlink.com

\begin{abstract}
We have previously developed a rapid, simple endoscopic method for evaluating gastrin-stimulated maximal acid output (the endoscopic gastrin test, EGT). In EGT, gastric fluid newly secreted over 10 min after gastrin stimulation is collected under direct endoscopic visualization. In this study, employing the EGT, we evaluated the effect of rebamipide, a cytoprotective anti-ulcer drug, on gastric mucus secretion. In ten Helicobacter pylori-negative healthy volunteers, gastric juice was collected by EGT prior to and after 4-week administration of rebamipide. The collected gastric juice was subjected to analysis for gastric mucus output. Total gastric mucin output was significantly increased by $53 \%$ by rebamipide administration from $3.2 \pm 1.2 \mathrm{mg}$ hexose $/ 10 \mathrm{~min}$ to $4.9 \pm 2.2 \mathrm{mg}$ hexose/ $10 \mathrm{~min}(P<0.01)$. Further analysis by ion-exchange chromatography revealed that rebamipide administration induced a specific increase in acidic mucin rich in sialic acid. Applying EGT, this study demonstrated that
\end{abstract}

K. Iijima $(\bowtie) \cdot$ T. Koike $\cdot$ S. Ohara $\cdot$ T. Shimosegawa

Division of Gastroenterology, Tohoku University Graduate

School of Medicine, 1-1 Seiryo-machi, Aobaku, Sendai,

Miyagi 980-8574, Japan

e-mail: jiijima@int3.med.tohoku.ac.jp

T. Ichikawa

Department of Biochemistry, Kitasato University School

of Medicine, Sagamihara, Kanagawa, Japan

S. Okada

Department of Biochemistry, Kitasato University School of Allied Health Sciences, Sagamihara, Kanagawa, Japan

M. Ogawa

GI Therapeutic Application Development Group, Otsuka

Pharmaceutical Co., Ltd., Yokohama, Japan rebamipide administration increased gastric mucus secretion in human.

Keywords Gastric mucus secretion ·

Gastric acid secretion · Gastric mucin · Rebamipide

\section{Introduction}

Gastric mucus forms a continuous mucus gel layer coating the entire gastric mucosa and plays an important role in the gastric defense mechanism against various noxious agents such as acid, pepsin, and swallowed material [1]. Several methods have been used to evaluate gastric mucus in human. Using biopsy specimens, the depth of the adherent mucus has been assessed occasionally with the aid of histochemical staining [2-4]. However, this approach allows only qualitative assessment of mucus at very focal sites where the biopsy specimens are taken; hence, it is not possible to estimate the amount of gastric mucus from the whole stomach quantitatively. Therefore, many other studies have undertaken quantitative assessments of gastric mucus using aspirated gastric juice, which contains a soluble form of gastric mucus [5-21]. Residual fasting gastric juice aspirated through an endoscope has been used to estimate gastric mucus secretion in some studies [5-8] because it is the most accessible; however, the composition of the fluid is dependent on many variables such as gastric acid and mucus secretion, and gastric emptying. In addition, contamination of the gastric aspirate by salivary mucus is inevitable in such an approach [9]. Hence, freshly secreted gastric juice continuously aspirated using a nasogastric tube under fasting and gastrin stimulation has been often employed for mucus analysis [9-21]. Although this approach could provide quantitative analysis of soluble mucus, the procedure 
usually requires more than an hour to aspirate secreted gastric juice collectively, and still a part of the secreted fluid is lost through the pylorus due to the blind aspiration.

We have previously developed a rapid, simple endoscopic method for evaluating gastrin-stimulated maximal acid output (the endoscopic gastrin test, EGT) [22]. In this method, gastric fluid freshly secreted over $10 \mathrm{~min}$ after gastrin stimulation is collected under direct endoscopic visualization. EGT enables routine endoscopic examination and stimulated acid secretory testing simultaneously within about $15 \mathrm{~min}$. Thus, since freshly secreted gastric juice is aspirated under direct visualization, precluding both its loss through the pylorus and contamination with saliva, the EGT can be employed for prompt, quantitative assessments of gastric mucus secretion.

Rebamipide is a cytoprotective anti-ulcer drug [23] that has been found to reduce the rate of recurrence of gastric ulcers, regardless of the presence or absence of $\mathrm{H}$. pylori infection [24]. Rebamipide has also been shown to be effective in preventing nonsteroidal anti-inflammatory drug (NSAID)-induced gastric mucosal injury [25, 26]. Previous animal studies indicated that one of the principal gastric defense mechanisms afforded by rebamipide was through the increase of gastric mucus secretion, probably resulting from the stimulation of endogenous prostaglandin production in the gastric mucosa [27]. However, direct evidence that the agent can increase gastric mucus secretion in human is lacking, probably due to the technical difficulty in assessing gastric mucus precisely.

In this study, employing the EGT technique to collect freshly secreted gastric juice, we evaluate the effect of 4-week oral administration of rebamipide on gastric acid and mucus secretion in healthy volunteers.

\section{Methods}

Ten $H$. pylori-negative healthy volunteers (nine men), all nonsmokers, with a mean age of 35 years (27-50 years) were enrolled in this study. Their $H$. pylori status was determined by ${ }^{13} \mathrm{C}$-urea breath test. None of the subjects were taking any drugs and were found to be normal by upper gastrointestinal endoscopy. In each subject, two series of experiments were conducted, at an interval of at least 4 weeks as the washout period, in a random sequence. One series comprised EGT prior to and after 4-week administration of rebamipide, and the other, as controls, comprised two EGTs at a 4-week interval without any treatment. One each occasion for EGT, the test was performed in the morning after overnight fast. In the treatment allocation, rebamipide was administered at a dose of $100 \mathrm{mg}$ three times a day, and the final dose of the drug was taken $2 \mathrm{~h}$ before performing EGT.
Gastric Aspiration with the EGT Technique

The details of EGT have been reported previously [22]. Briefly, subjects were injected intramuscularly with pentagastrin at a dose of $6 \mu \mathrm{g} / \mathrm{kg}$ (pentagastrin; Sigma, St. Louis, Mo, USA) about 15 min before the endoscopy. On entering the stomach with the endoscope, the gastric fluid pooled in the stomach was aspirated and discarded. Then, gastric juice newly secreted between 20 and $30 \mathrm{~min}$ after the pentagastrin injection was aspirated and collected under direct visualization during the routine endoscopic examination. During the examination, the subjects were asked not to swallow their saliva. After the collection of gastric juice, the endoscope was removed. The volume of gastric juice collected in the 10-min period was recorded and then the collected gastric juice was divided, with one half subjected to analysis for gastric acid secretion and the other used for analysis of gastric mucus secretion. During the laboratory work the investigators were blinded to the subjects' allocation.

\section{Assessment of Gastric Acid Secretion}

The $\mathrm{H}^{+}$concentration of the gastric juice was determined by titration. Acid output in the 10-min period was calculated by multiplying the volume by the $\mathrm{H}^{+}$concentration, and the EGT value was expressed in units of $\mathrm{mEq} / 10 \mathrm{~min}$. We have previously shown that EGT values correlate very well with the peak acid output determined by conventional methods (correlation coefficient of 0.92) with high reproducibility (coefficient of variation of 5.6\%) [22].

\section{Extraction and Isolation of Mucin in Gastric Juice}

The collected gastric juice was centrifuged at $1,500 \times g$ for $30 \mathrm{~min}$ at room temperature to remove the contaminating debris. The mucin in the gastric juice samples was extracted and isolated by a previously described method [28]. This method could successfully isolate and condense the mucin from the gastric juice, without contamination by nonmucin glycoproteins such as serum-type glycoproteins. Absolute ethanol $(6 \mathrm{ml})$ was added to $2 \mathrm{ml}$ of the supernatant obtained from the gastric juice to make a $75 \%(\mathrm{v} / \mathrm{v})$ ethanol concentration. The resultant suspension was maintained at $4^{\circ} \mathrm{C}$ overnight to complete the precipitation, after which the precipitate was collected by centrifugation $\left(8,000 \times g\right.$ for $30 \mathrm{~min}$ at $\left.4^{\circ} \mathrm{C}\right)$. The pellet was dissolved in distilled water $(2 \mathrm{ml})$ and its hexose content was measured by the phenol-sulfuric acid method. The mucin content of the gastric juice was expressed as the hexose amount in the solution obtained by the precipitation method $(\mu \mathrm{g} / \mathrm{ml})$. The mucin output was determined by multiplying the mucin concentration by the volume of gastric juice collected in the 10-min period. 


\section{Fraction of Human Gastric Mucin}

The mucins were fractionated by ion-exchange chromatography as described previously $[5,6]$. The mucin solution obtained was digested with $1 \mathrm{mg} / \mathrm{ml}$ chymotrypsin, extensively dialyzed against deionized water, lyophilized, and redissolved in $10 \mathrm{mmol} / \mathrm{l}$ Tris- $\mathrm{HCl}, \mathrm{pH} \mathrm{7.2}$. The sample was applied to a $5 \times 50 \mathrm{~mm}$ ion-exchange column containing DEAE-Sepharose CL-6B (Phamacia Fine Chemicals, Sweden) and eluted at $1 \mathrm{ml} / \mathrm{min}$ with a discontinuous gradient concentration of $\mathrm{NaCl}(0,0.25,0.5$, $1.0 \mathrm{~mol} / \mathrm{l}$ ) in $10 \mathrm{mmol} / \mathrm{l}$ Tris- $\mathrm{HCl}, \mathrm{pH} \mathrm{7.2}$. The effluent solution was checked by hexose measurement and the mucin recovery was found to be approximately $90 \%$.

\section{Statistics}

Data are expressed as the mean \pm standard deviation (SD) and Student's paired $t$ test was used to compare the results between the two studies, either for rebamipide administration or for controls. $P$-value $<0.05$ was considered to be statistically significant. The study was approved by Tohoku University School of Medicine Ethics Committee and each subject gave written informed consent.

\section{Results}

The volume of the aspirated samples collected with the EGT from 40 individual tests in the present study ranged from 19 to $56 \mathrm{ml}$, with an average of $37 \mathrm{ml}$, which was sufficient for the analysis for both gastric acid and mucus in each occasion. The overall results for various parameters of the gastric aspirates collected by EGT are listed in Table 1.

The volume of secreted gastric fluid was not significantly different between prior to and after 4-week administration of rebamipide (prior to: $35.4 \pm 8.1 \mathrm{ml}$ versus after: $33.0 \pm 7.3 \mathrm{ml}$ ) (Table 1; Fig. 1). Regarding the effects of rebamipide on gastric acid secretion, the administration did not significantly alter gastric acidity (prior to: $107.4 \pm 27.2 \mathrm{mEq} / \mathrm{l}$ versus after: $120.0 \pm 15.9 \mathrm{mEq} / \mathrm{l})$ nor total gastric acid output (prior to: $3.8 \pm 1.2 \mathrm{mEq} / 10 \mathrm{~min}$ versus after: $4.0 \pm 1.3 \mathrm{mEq} / 10 \mathrm{~min}$ ).

In contrast, rebamipide affected gastric mucus secretion assessed by determination of both the mucin concentration and total mucin output of gastric aspirates. Both parameters were increased by rebamipide administration in all but two subjects. The mean mucin concentration prior to rebamipide administration was $93.6 \pm 37.8 \mu \mathrm{g}$ hexose/ml and was significantly increased to $155.8 \pm 81.3$ after the

Table 1 Changes in various parameters of gastric aspirates collected by the EGT

\begin{tabular}{lccccccc}
\hline & \multicolumn{2}{l}{ On rebamipide $(n=10)$} & & \multicolumn{2}{l}{ Drug free $(n=10)$} \\
\cline { 2 - 3 } & First exam & Second exam & $P$ value & & First exam & Second exam & $P$ value \\
\hline Secreted volume $(\mathrm{ml})$ & $35.4 \pm 8.1$ & $33.0 \pm 7.3$ & N.S. & & $36.6 \pm 8.7$ & $38.6 \pm 12.5$ & N.S. \\
Acidity $(\mathrm{mEq} / \mathrm{l})$ & $107.4 \pm 27.2$ & $120.0 \pm 15.9$ & N.S. & $118.3 \pm 13.5$ & $116.7 \pm 11.9$ & N.S. \\
Total acid output $(\mathrm{mEq} / 10 \mathrm{~min})$ & $3.8 \pm 1.2$ & $4.0 \pm 1.3$ & N.S. & $4.3 \pm 0.8$ & $4.4 \pm 1.2$ & N.S. \\
Mucin concentration $(\mu \mathrm{g}$ hexose/ml) & $93.6 \pm 37.8$ & $155.8 \pm 81.3$ & $<0.01$ & $98.4 \pm 84.8$ & $89.7 \pm 63.5$ & N.S. \\
Total mucin output $(\mathrm{mg}$ hexose/10 min) & $3.2 \pm 1.2$ & $4.9 \pm 2.2$ & $<0.01$ & $3.5 \pm 3.3$ & $3.7 \pm 5.5$ & N.S. \\
\% Of acidic mucin & $31.5 \pm 7.8$ & $39.6 \pm 12.1$ & $<0.05$ & & $28.8 \pm 12.7$ & $29.4 \pm 11.1$ & N.S. \\
\hline
\end{tabular}

NS, not significant. Data represents mean \pm SD

Fig. 1 Changes in volume of gastric aspirates collected with the endoscopic gastrin test (EGT). Gastric aspirates were collected by EGT prior to and after 4-week rebamipide administration (a), or at a 4-week interval without any treatment (b). There were no significant differences between the two occasions in either group. NS, not significant
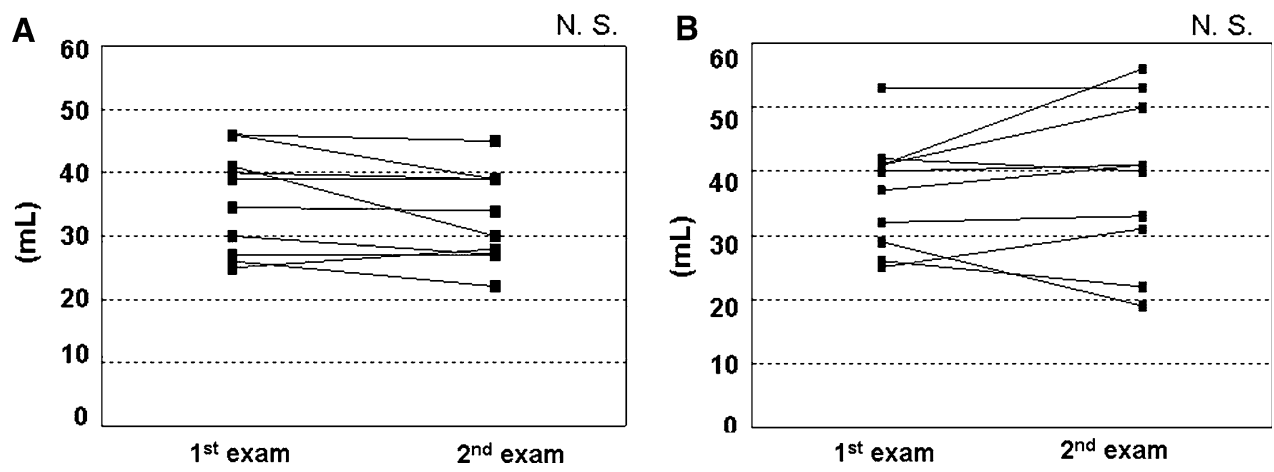
4-week administration $(P<0.01)$ (Table 1; Fig. 2). Consequently, total gastric mucin output was significantly increased by $57 \%$ by rebamipide administration from a mean value of $3.2 \pm 1.2 \mathrm{mg}$ hexose $/ 10 \mathrm{~min}$ pre treatment to $4.9 \pm 2.2$ post treatment $(P<0.01)$ (Table 1; Fig. 3).

To examine which constituent of the gastric mucins was increased by the rebamipide administration, the gastric mucins extracted from the gastric aspirates were divided into three fractions (Fr. I, Fr. II, and Fr. III) by ionexchange chromatography. Figure 4 shows a typical DEAE-Sepharose chromatography elution pattern of the mucins prior to and after rebamipide administration, revealing that rebamipide administration increased gastric mucin secretion specifically by augmenting Fr. III mucin. We previously reported that these mucin fractions corresponded to compositionally distinct mucin species using
Fig. 2 Changes in gastric mucin concentration at 4 -week interval by rebamipide (a) or in drug-free controls (b). Gastric aspirates were collected by EGT and the amounts of gastric mucin were defined by the hexose contents. The gastric mucus concentration was significantly increased by rebamipide administration while it was unchanged in the drugfree controls. NS, not significant
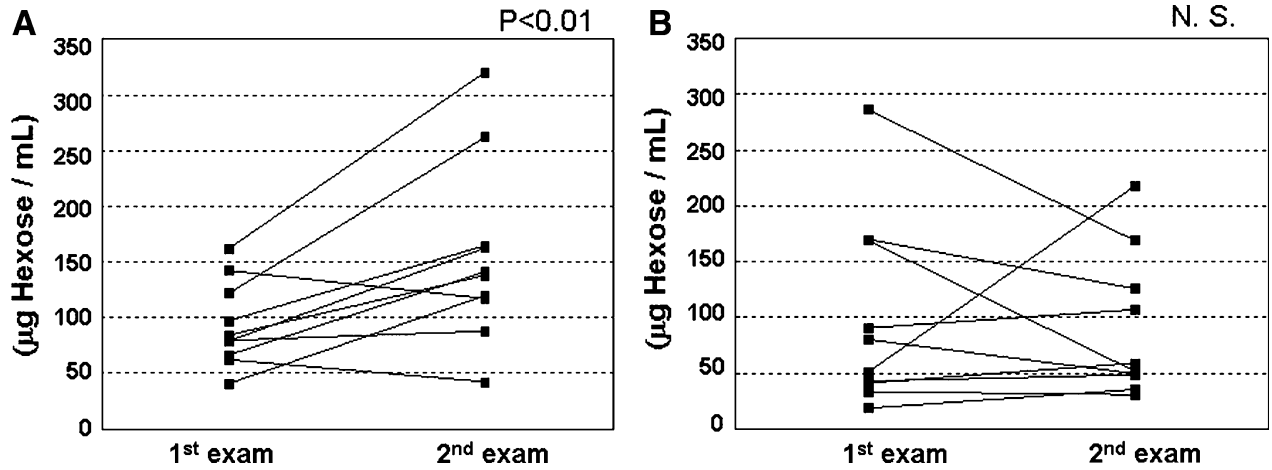

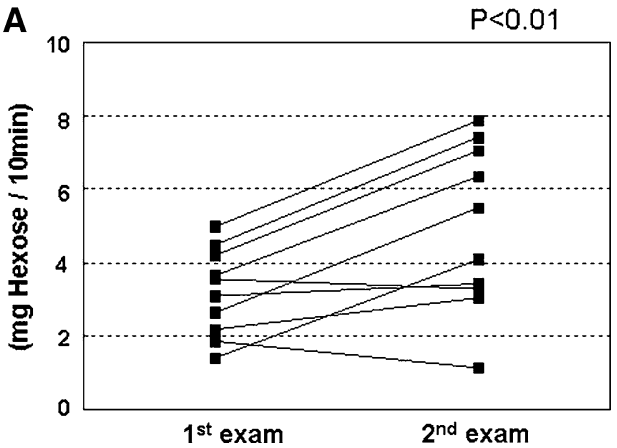

Fig. 3 Changes in gastric mucin output at 4-week interval by rebamipide (a) or drug-free controls (b). Gastric aspirates were collected by EGT and the amounts of gastric mucin were defined by

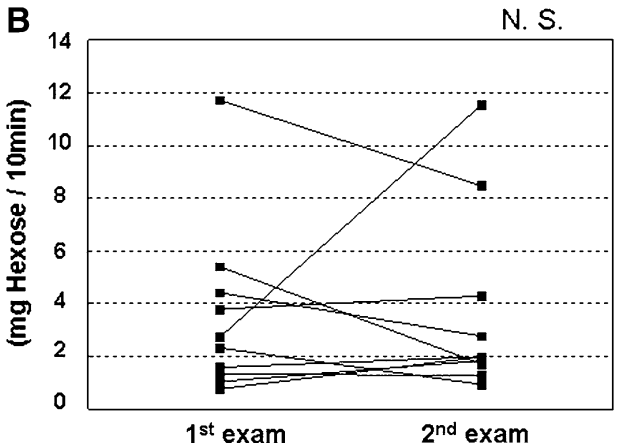

the hexose contents. Gastric mucus output was significantly increased by rebamipide administration whereas it did not change in the drugfree controls. NS, not significant
Fig. 4 A representative case showing the changes in the constituents of the gastric mucin by ion-exchange chromatography prior to and after rebamipide administration. Gastric mucins extracted from the gastric aspirates were divided into three fractions (Fr. I, Fr. II, and Fr. III). Rebamipide administration increased specifically Fr. III mucin, namely acidic mucin

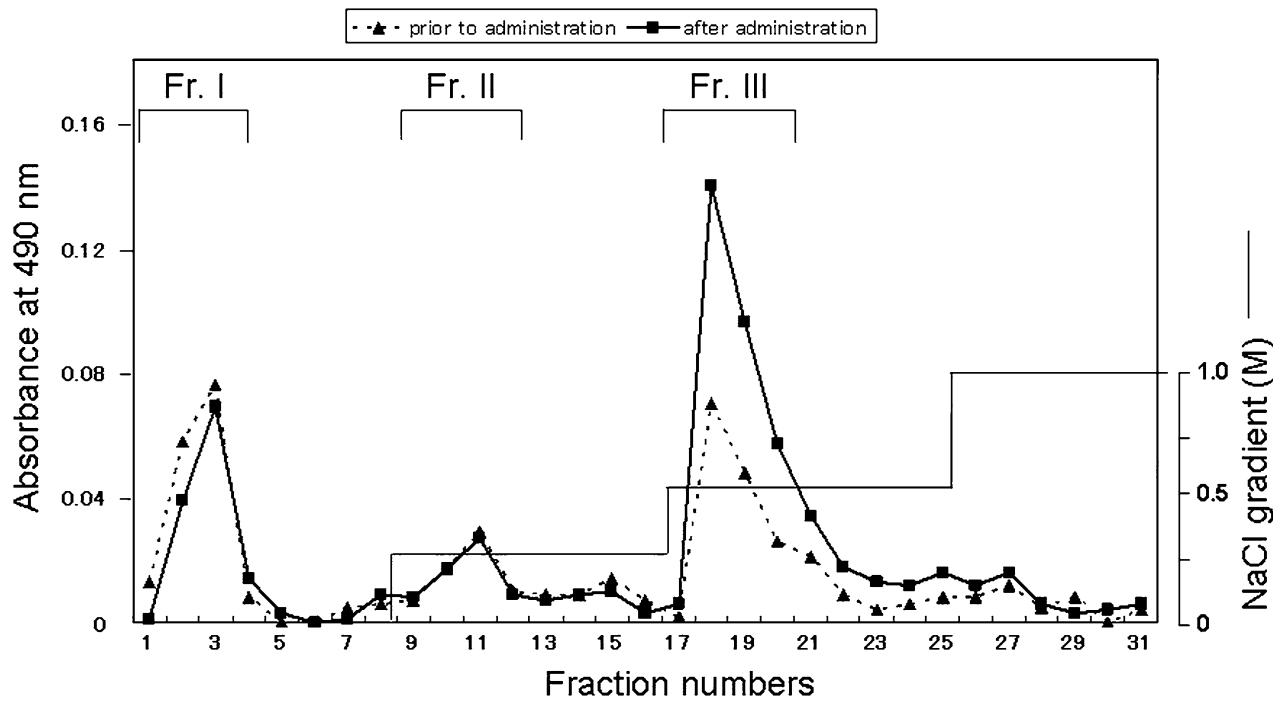


Fig. 5 Changes in the percentage of acidic mucin in total mucin content at 4 -week interval by rebamipide (a) or in drug-free controls (b).

Proportions of acidic mucin were significantly increased by rebamipide administration while they did not change in controls. NS, not significant
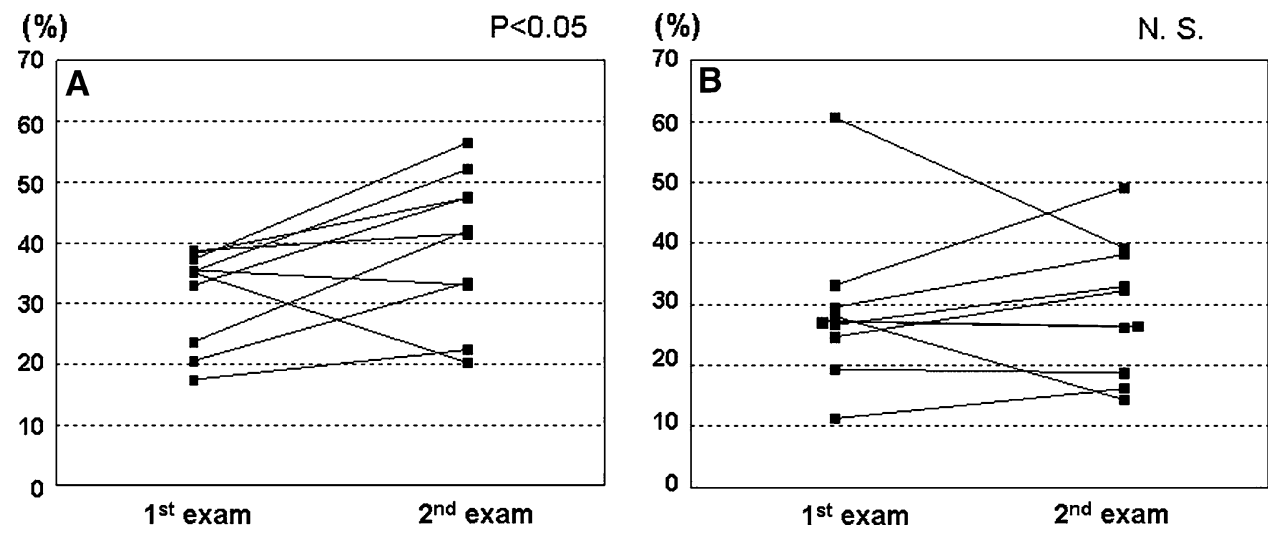

gas-liquid chromatography, and that Fr. III mucin represented acidic mucin involving much more sialic acid as a constituent compared with Fr. 1 or Fr. II $[5,6]$. Consequently, the percentage of Fr. III, that is, the acidic mucin in the total mucin content, was significantly increased from $32 \%$ to $40 \%$ by rebamipide administration $(P<0.05)$ (Table 1; Fig. 5). In one of the two patients who exhibited a decline in total mucin output on rebamipide (Fig. 3a), the percentage of acidic mucin was also decreased (Fig. 5a).

In the controls, in which EGT was repeated on two separate days at a 4-week interval without any treatment, no parameters analyzed changed between the two occasions (Table 1).

\section{Discussion}

Using gastric juice samples collected with the EGT technique, this study demonstrated that rebamipide, a cytoprotective anti-ulcer drug, administered at the commonly used dosage during 4 weeks, caused a significant increase in gastric mucus secretion while the drug did not significantly modify secretory volume nor gastric acid secretion. This finding in human confirms previous observations from animal studies [27], supporting the view that one potential mechanism of the anti-ulcer efficacy elicited by rebamipide administration results from enhancement of the gastric mucosal defense action by stimulating gastric mucus secretion.

There are two physical forms of the gastric mucus: one consists of a thin layer adherent to the gastric mucosa, and the second component is soluble mucus that contains mucus cleaved by pepsin degradation [29] or newly secreted with acid as a separate unit [30]. The adherent mucus normally covers the gastric mucosa and acts as a protective physical barrier against noxious luminal agents. However, since the adherent mucus is not collected by the aspiration of gastric juice, quantitative assessment of this material is difficult. Therefore, soluble mucus has been employed as an index of gastric mucus secretion on the assumption that it has reached a steady-state relationship with the adherent mucus. Thus, analysis of soluble mucus using gastric aspirates has generally been applied to estimate gastric mucus secretion in many studies that have investigated the effects of various kinds of drugs on gastric mucus secretion [10-20].

In examining gastric acid secretion, provoking the maximal gastric secretory state stimulated by pentagastrin is essential to obtain reproducible results by neglecting variable effects from other factors. Similarly, stimulation by pentagastrin is advantageous for examining gastric mucus secretion as well as lowering the mucus viscosity by dilution due to the enhanced gastric secretory volume [16]. In addition, pentagastrin, by lowering the gastric luminal $\mathrm{pH}$, has been reported to function as a strong stimulus for mucin release from the mucous cells [31, 32], and this property also facilitates the recovery of gastric mucus and the correct timing of collections under a pentagastrinstimulated condition.

The EGT was devised originally to estimate gastric acid secretion during endoscopic examination in order to shorten the conventional time-consuming procedure in which gastric juice was collected through a nasogastric tube. In EGT, both facilitated recovery with a stimulant injection and precise aspiration of gastric juice under direct endoscopic visualization enable accurate estimation of gastric acid secretion with high reproducibility, despite the short duration of the procedure, requiring only $10 \mathrm{~min}$ for collecting the gastric juice [22]. In this study, we applied the EGT technique for prompt, quantitative analysis of gastric mucus secretion in human.

Regarding the time course of the gastric mucus secretory response to a stimulant injection, previous studies indicated that the response reached a plateau within $30 \mathrm{~min}$ of the injection [14, 17]. Hence, the gastric aspirates obtained at 20-30 min after intramuscular pentagastrin injection, when the gastric juice is collected with the EGT technique, represented the peak or near-peak mucus secretory 
response to the stimulant. In analyzing the reproducibility of gastric acid and mucus secretion with the EGT technique based on the present results in controls, the median coefficient of variations was $10.3 \%(0.7-23.4 \%)$ for the gastric acid secretion while it was $35.6 \%$ (3.8-87.3\%) for mucus secretion. The high reproducibility of gastric acid secretion with the EGT was consistent with our original report (coefficient of variation 5.6\%) [22]. In contrast, the reproducibility turned out to be rather poor for gastric mucus secretion, especially in a few cases in which the differences between the two results was more than a factor of two. Although, as far as we know, no previous reports have investigated the reproducibility of gastric mucus secretion, relatively poor reproducibility might be expected for such analyses. One possible reason for the lower reproducibility of gastric mucus analysis compared with gastric acid is that gastric mucus secretion can be affected by various factors other than pentagastrin stimulation, resulting in variable results, while gastric acid can be maximally stimulated with pentagastrin and therefore tends to show consistent results. Therefore, in assessing gastric mucus secretion using gastric aspirates, it is necessary to take into account its relatively poor reproducibility.

Despite such limitations in estimating the gastric mucus secretion using aspirated samples, the present study successfully demonstrated in human that 4-week rebamipide administration significantly increased the mucin concentration of the gastric aspirate while it did not modify the secretory volume, resulting in a significant increase in total mucin output. Since previous studies also indicated that increases in gastric mucus secretion were yielded by administering other cytoprotective drugs such as misoprostol [20] or teprenone [11] in human, this could be a common feature in this type of agent that contributes to their anti-ulcer efficacy. Rebamipide elevates gastric mucus secretion, probably by increasing the generation of gastric mucosal prostaglandin $\mathrm{E}_{2}$, which is known to be a strong stimulant for gastric mucus secretion [14]. Hence, the increase in the soluble mucus yielded by rebamipide administration in this study is likely to reflect an increase in the newly secreted adherent mucus, which is considered to be more important as a protective physical barrier of the gastric epithelium. Although prostaglandin $\mathrm{E}_{2}$, especially at a higher dose, can function as a potent inhibitor of gastric acid secretion as well, our present results indicate that rebamipide, at least at the commonly used dosage, does not affect gastric acid secretion in human. In this study, we evaluated the effect of 4-week administration of rebamipide, which is a commonly recognized treatment period for gastric ulcers, although shorter administration of the drug may be sufficient to induce a stimulatory effect on gastric mucus secretion, as shown in other cytoprotective drugs $[11,20]$.
In the present study, rebamipide administration did not induce any measurable increase in gastric mucus secretion in three subjects, and they could be nonresponders to the treatment. It would be intriguing to investigate the link between the effect of rebamipide on gastric mucus secretion and the clinical cytoprotective property of the drug in human. On the other hand, since it has been reported that rebamipide also exerts cytoprotective effect through other mechanisms such as free-radical scavenging or attenuation of neutrophil activity [23], further studies are required to clarify the precise mechanism of action of the drug.

Mucin, a highly glycosylated glycoprotein with high molecular weight, is a major component of gastric mucus. We previously reported that the human gastric luminal mucins can be fractionated into three major components according to the ratio of sialic acid to other carbohydrate components $[5,6]$. Further analysis of the mucin composition in the present study revealed that the increase in total mucin output induced by rebamipide administration was due predominantly to the increase in Fr. III mucin, which corresponds to acidic mucin rich in sialic acid. This specific elevation of a mucin fraction by rebamipide administration has not been reported in previous studies utilizing other cytoprotective drugs. The increased total mucin output elicited by rebamipide administration, and in particular the elevated fraction of acidic mucin rich in sialic acid, may have clinical implications for the gastric mucosal defense mechanism. Sialic acid is linked to the monosaccharides, giving electronegative charges to the glycoprotein molecule, a chief constituent of the mucin structure, and thus the presence of sialic acid residue in mucins may contribute to enhanced interaction between the mucins and other chemical species, resulting in facilitated boundary lubrication and reducing damage to the gastric mucosa [33]. In addition, the mucus charge elicited by the presence of sialic acid residues can also contribute to the high viscosity of mucin, leading to enhancement of the gastric barrier function [34].

Whether the different fractions of mucins presented in this study are secreted by different types of epithelial or glandular cells, or whether all of them are produced by the same cells in the gastric mucosa, remains to be clarified. The gastric mucosa has two types of mucin-secreting cells: surface mucous cells and gland mucous cells [35, 36]. Accumulating evidence suggests that gastric mucins secreted by distinct types of gastric mucus cells operate differently in the gastric defensive mechanism [37-40]. A recent molecular biological approach using a monoclonal antibody enables quantitative determination of gastric mucins in human gastric juice that originate from two distinct types of mucin-secreting cells [41]. Further studies, combined with such an approach, will help identify the 
origin of the specific mucin secretion elicited by rebamipide administration and clarify the precise effect of rebamipide on gastric mucus secretion in relation to the gastric defense mechanism.

In conclusion, applying the EGT technique for aspirating gastric juice, this study demonstrated that 4-week administration of rebamipide at the commonly used dosage induced an increase in gastric mucus secretion in human while it did not affect gastric acid secretion. This observation could contribute to understanding one of the underlying mechanisms in the cytoprotective anti-ulcer property of rebamipide. Assessing both gastric acid and mucus secretion with the EGT technique during routine endoscopy may provide valuable information regarding the state of gastric aggressive and defensive factors concurrently with endoscopic changes of the gastric mucosa. This will be particularly useful to evaluate the effect of gastropathy-inducible agents, such as NSAID or aspirin, on the integrity of the gastric mucosa.

Open Access This article is distributed under the terms of the Creative Commons Attribution Noncommercial License which permits any noncommercial use, distribution, and reproduction in any medium, provided the original author(s) and source are credited.

\section{References}

1. Allen A, Flemstrom G. Gastroduodenal mucus bicarbonate barrier protection against acid and pepsin. Am J Physiol Cell Physiol. 2005;288:C1-C19.

2. Hidaka E, Ota H, Hidaka H, et al. Helicobacter pylori and two ultrastructurally distinct layers of gastric mucous cell mucins in the surface mucous gel layer. Gut. 2001;49:474-480. doi: 10.1136/gut.49.4.474.

3. Sarosiek J, Marshall BJ, Peura DA, Hoffman S, Feng T, MvCallum RW. Gastroduodenal mucus gel thickness in patients with Helicobacter pylori: a method for assessment of biopsy specimens. Am J Gastroenterol. 1991;86:729-734.

4. Jordan N, Newton J, Pearson J, Allen A. A novel method for the visualization of the in situ mucus layer in rat and human. Clin Sci. 1998;95:97-106. doi:10.1042/CS19980081.

5. Ikezawa $\mathrm{T}$, Ichikawa $\mathrm{T}$, Adachi $\mathrm{K}$, et al. Analysis of mucin composition in gastric juices of chronic rheumatic patients with upper gastrointestinal damage. Biomed Res. 2005;26:147-151. doi:10.2220/biomedres.26.147.

6. Ichikawa T, Koizumi W, Takeuchi H, et al. A new strategy for evaluation of the eradication treatment of Helicobacter pylori: validation of the analysis of mucin composition in human gastric juice. Clin Chim Acta. 2001;303:69-73. doi:10.1016/S00098981(00)00377-6.

7. Marcinkiewicz M, Peura DA, Sarosiek J. The relationship between the content of aggressive and protective components in gastric juice and endoscopic findings after naproxen sodium and acetaminophen administration. Am J Gastroenterol. 1996;91:360-365.

8. Niv Y, Hardy B, Koren R, Rodiomov G, Fraser GM. Association between gastric acid and mucin secretion in dyspeptic patients. Digestion. 2002;65:141-148. doi:10.1159/000064934.

9. Pasquier MC, Vatier J, Poitevin C, Vallot T, Mignon M. Assessment of mucus glycoprotein erosion by measurement of sialic acid in gastric secretion: Pathophysiologic and therapeutic aspects. J Clin Gastroenterol. 1991;13(suppl 1):S22-S31. doi: 10.1097/00004836-199112001-00005.

10. Jaworski T, Sarosiek I, Sostarich S, et al. Restorative impact of rebeprazole on gastric mucus and mucin production impairment during naproxen administration: its potential clinical significance. Dig Dis Sci. 2005;50:357-365. doi:10.1007/s10620-005-1611-3.

11. Aono M, Moriga M, Mizuta K, Uchino H. Effect of teprenone o the content of phospholipids in gastric secretion in man. $J$ Gastroenterol. 1986;21:454-458.

12. Ene MD, Clamp JR, Roberts CJC. Effects of cimetidine and carbenoxolone on gastric mucus. Gut. 1988;29:636-641. doi: 10.1136/gut.29.5.636.

13. Baron JH, Barr J, Batten J, Sidebotham R, Spencer J. Acid, pepsin, and mucus secretion in patients with gastric and duodenal ulcer before and after colloidal bismuth subcitrate (De-Nol). Gut. 1986;27:486-490. doi:10.1136/gut.27.5.486.

14. Lee SP, Nicholls JF, Robertson AM. Effects of trimoprostil, a prostaglandin $\mathrm{E}_{2}$ analogue, on human gastric acid secretion and soluble mucin output. Eur J Clin Invest. 1987;17:1-6. doi: 10.1111/j.1365-2362.1987.tb01217.x.

15. Johansson C, Kollberg B. Stimulation by intragastrically administered $\mathrm{E}_{2}$ prostaglandins of human gastric mucus output. Eur J Clin Invest. 1979;9:229-232. doi:10.1111/j.1365-2362. 1979.tb00928.x.

16. Johansson C, Aly A. Stimulation of gastric mucus output by somatostatin in man. Eur J Clin Invest. 1982;12:37-39. doi: 10.1111/j.1365-2362.1982.tb00937.x.

17. Wilson DE, Levendoglu H, Adams A, Ramsamooj E. A new PGE1 (CL115, 574)III Effects on gastric acid and mucus secretion in man. Prostaglandins. 1984;28:5-11. doi:10.1016/00906980(84)90109-6.

18. Parodi MC, Molinari F, Barocci S. Influence of cytoprotective drugs (Carbenoxolone, Zolomidine, prostanoic acid) on mucus secretion in patients with gastric ulcer. Scand J Gastroenterol. 1984;19(suppl 92):163-166.

19. Skoczylas T, Sarosiek I, Sostarich S, McElhinney C, Durham S, Saroseik J. Significant enhancement of gastric mucin content after rabeplazole administration Its potential clinical significance in acid-related disorders. Dig Dis Sci. 2003;48:322-328. doi: 10.1023/A:1021983611768.

20. Wilson DE, Quadros E, Rajapaksa T, Adams A, Noar M. Effects of misoprostol on gastric mucus secretion in man. Dig Dis Sci. 1986;31(suppl 2):126S-129S. doi:10.1007/BF01309336.

21. Molinari F, Parodi MC, De Angelis P, Cheli R. Gsatric mucus secretion in chronic gastritis. Scand J Gastroenterol. 1984;19 (suppl 92):167-171.

22. Iijima K, Ohara S, Sekine H, et al. A new endoscopic method of gastric acid secretory testing. Am J Gastroenterol. 1998;93:21132118. doi:10.1111/j.1572-0241.1998.00603.x.

23. Arakawa T, Kobayashi K, Yoshikawa T, Tarnawski A. Rebamipide: overview of its mechanisms of action and efficacy in mucosal protection and ulcer healing. Dig Dis Sci. 1998;43(suppl 9):5S-13S.

24. Terano A, Arakawa T, Sugiyama T, et al. Rebamipide, a gastroprotective and anti-inflammatory drug, promotes gastric ulcer healing following eradication therapy for Helicobacter pylori in a Japanese population: a randomized, double-blind, placebo-controlled trial. J Gastroenterol. 2007;42:690-693. doi:10.1007/ s00535-007-2076-2.

25. Kim HK, Kim JI, Kim JK, et al. Preventive effects of rebamipide on NSAID-induced gastric mucosal injury and reduction of gastric mucosal blood flow in healthy volunteers. Dig Dis Sci. 2007;52:1776-1782. doi:10.1007/s10620-006-9367-y.

26. Park SH, Cho CS, Lee OY, et al. Comparison of prevention of NSAID-induced gastrointestinal complications by rebamipide 
and misoprostol: a randomized, multicenter, controlled trialSTORM STUDY. J Clin Biochem Nutr. 2007;40:148-155. doi: 10.3164/jcbn.40.148.

27. Yamazaki K, Kanbe T, Chijiwa T, Ishiyama H, Morita S. Gastric mucosal protection by OPC-12759, a novel antiulcer compound, in the rat. Eur J Pharmacol. 1987;142:23-29. doi:10.1016/00142999(87)90649-2.

28. Azuumi Y, Ichikawa T, Ishihara K, Hotta K. The validity of the ethanol precipitation method for the measurement of mucin content in human gastric juices and its possible relationship to gastroduodenal diseases. Clin Chim Acta. 1993;221:219-225. doi:10.1016/0009-8981(93)90037-5.

29. Pearson JP, Allen A, Venables CW. Gastric mucus: isolation and polymeric structure of the undegraded glycoprotein: its breakdown by pepsin. Gastroenterology. 1980;78:709-715.

30. Bhaskar KR, Garik P, Turner BS, et al. Viscous fingerprint of $\mathrm{HCl}$ through gastric mucin. Nature. 1992;360:458-461. doi: $10.1038 / 360458 \mathrm{a} 0$.

31. Ichikawa T, Ishihara K, Kusakabe T, et al. Distinct effects of tetragastrin, histamine, and $\mathrm{CCh}$ on rat gastric mucin synthesis and contribution of NO. Am J Physiol. 1998;274:G138-G146.

32. Scheiman JM, Kraus ER, Boland CR. Regulation of canine gastric mucin synthesis and phospholipids secretion by acid secretagogues. Gastroenterology. 1992;103:1842-1850.

33. Yusuf S, Nok AJ, Ameh DA, Adelaiye AB, Balogun EO. Correlation of gastric mucosal damage with sialic acid profile in rats: effect of hydrochloric acid, pepsin and hypertonic saline. Cell Biochem Funct. 2005;23:339-345. doi:10.1002/cbf.1156.

34. Yakubov GE, Papagiannopoulos A, Rat E, Waigh TA. Charge and interfacial behavior of short side-chain heavily glycosylated porcine stomach mucin. Biomacromolecules. 2007;8:3791-3799. doi:10.1021/bm700721c.
35. Ho SB, Roberton AM, Shekels LL, Lyftogt Ct, Niehans GA. Toribara NW Expression cloning of gastric mucin complementarty DNA and localization of mucin gene expression. Gastroenterology. 1995;109:735-747. doi:10.1016/0016-5085 (95)90380-1.

36. Ota H, Katsuyama T, Ishii K, Nakayama J, Shiozawa T, Tsukahara Y. A dual staining method for identifying mucins of different gastric epithelial mucous cells. Histochem J. 1991; 23:22-28. doi:10.1007/BF01886504.

37. Goso Y, Ikezawa T, Kurihara M, Endo M, Hotta K, Ishihara K. Characterization of rat gastric mucins using a monoclonal antibody, RGM23, recognizing surface mucous cell-type mucins. $J$ Biochem. 2003;133:453-460. doi:10.1093/jb/mvg059.

38. Goso Y, Ishihara K, Kurihara M, Sugaya T, Hotta K. Rat gastric mucins recognized by monoclonal antibodies RGM21 and HIK1083: Isolation of mucin species characteristic of the surface and grandular mucosa. J Biochem. 1999;126:375-381.

39. Ikezawa T, Goso Y, Ichikawa T, et al. Appearance of specific mucins recognized by monoclonal antibodies in rat gastric mucosa healing from $\mathrm{HCl}$-induced gastric mucosal damage. J Gastroenterol. 2004;39:113-119. doi:10.1007/s00535-003-1261-1.

40. Ota H, Hayama M, Nakayama J, et al. Cell lineage specificity of newly raised monoclonal antibodies against gastric mucins in normal, metaplastic, and neoplastic human tissues and their application to pathology diagnosis. Am J Clin Pathol. 2001; 115:69-79. doi:10.1309/AMUR-K5L3-M2DN-2DK5.

41. Kubota S, Yamauchi K, Kumagai T, et al. Quantitative determination of gland mucous cells-type mucin using a monoclonal antibody, HIK1083: its pathophysiological changes in human gastric juice. Clin Chim Acta. 2007;377:261-267. doi: 10.1016/j.cca.2006.10.011. 